\title{
Note on Measures and Transliteration
}

$1 m u=1 / 15$ hectares $=1 / 6$ acre

1 in $=0.5$ kilogram $=1.1$ pounds

100 jin $=1$ shidan $($ dan $)$

$10 \mathrm{fen}=1 \mathrm{mao}$

10 mao $=1$ yuan

1 yuan = from approximately U.S. $\$ 0.40$ to $\$ 0.279$ (value has decreased since the late 1970s)

All transliteration of Chinese terms is in the pinyin system of romanization of Mandarin (putonghua). 
This page intentionally left blank 